Florian Busch*

\title{
Enregistered spellings in interaction
}

\section{Social indexicality in digital written communication}

https://doi.org/10.1515/zfs-2021-2033

\begin{abstract}
Against the backdrop of the societal differentiation of literacy, the paper investigates spelling variation in digital written communication beyond the binary paradigm of standard and nonstandard. To this end, the paper proposes a formal classification of digital spelling variants and then focuses on the sociocommunicative functions of these variants in usage. Theoretically grounded in the notions of register and social indexicality, the paper discusses how spelling variants are metapragmatically ordered by social actors and deployed in textmessaging interactions in order to indicate interpretive context. To investigate these phenomena holistically, the paper furthermore presents a tripartite research framework that addresses digital writing regarding its I) structural variants, II) communicative practice, and III) reflexive awareness. Afterwards, this methodological approach is applied empirically. This is done based on a data set that includes samples of everyday literacy by 23 German adolescents: informal WhatsApp texting, on the one hand, formal school essays on the other. The exemplary analyses focus on phonostylistic spellings (e. g. elisions such as <ich hab> instead of $<$ ich habe $>$ ) and graphostylistic spellings (e. g. graphemic substitutions such as $\langle$ daß $>$ instead of $<$ dass $>$ ) in these WhatsApp interactions, reconstructing the metapragmatic status of standard orthography in digital writing. By combining structure-oriented, interactional, and ethnographic perspectives, the paper seeks a disciplinary dialogue by relating concepts of sociolinguistics and linguistic anthropology not only to research fields of media linguistics but also to research on writing systems.
\end{abstract}

Keywords: spelling variation, German orthography, social indexicality, digital communication, WhatsApp interaction

\footnotetext{
*Corresponding author: Florian Busch, Germanistisches Institut, Martin-Luther-Universität Halle-Wittenberg, Adam-Kuckhoff-Str. 15, 06108 Halle (Saale), Germany, e-mail: florian.busch@germanistik.uni-halle.de
} 


\section{Introduction}

The role of writing and literacy has changed in the course of the digitization in everyday communication - not only at the level of individual writers, whose everyday life incorporates more literacy events than ever before, but also by unfolding a catalytic effect on linguistics' view of written language and its communicative and social variability. Even though literacy practices were already highly variable in pre-digital times, always sociolinguistically shaped in the nexus of social actors in specific contexts (cf. Elspaß 2002), the proliferation of digital media marks a new chapter of literacy and certainly a new era of literacy studies (cf. Gee 2015). This also applies to the linguistic study of spelling in particular. Facing the everyday practices of digital literacy, the rigid binary division between orthographic standard spelling as a linguistic default and non-standard spelling as quantitatively marginal and qualitatively deviant proves questionable. Instead, in the age of digital communication everyday literacy turns out to be fragmented into a plethora of communicative practices-a kaleidoscope of writing styles, each assigned to social situations and identities on the basis of socially shared language and media ideologies (cf. Androutsopoulos 2016; Busch 2018; 2021a). In this perspective, the evolution of writing systems cannot be separated from the evolution of communication media and, most importantly, from the pluralization of communicative practices conducted by social actors using these media. In this paper, I will explore these practices at the level of graphemic variation in German texting and show how distinctive spelling variants become resources of socially meaningful registers of digital writing.

In my understanding, the term digital writing does not only indicate the specific technological conditions of the production process but also highlights the embedding of written communication in a mediated network of mutual interlocutors. Digital writing in this sense is not merely writing of any kind by means of computerized technology (e. g. writing an essay on a desktop computer), but rather refers to written communication that is characterized by its interactiveness and sequential structure and organization (cf. Georgakopoulou 1997; Androutsopoulos 2007; Storrer 2018). While spoken conversations are built up by turns, the basic interactional unit of digital writing practices is the message. A message is constituted by all the semiotic means that an interlocutor selects by typing before sending it by one final click/tap as a delimited visual contribution, mostly displayed in the shape of a speech bubble by the software application. ${ }^{1}$ These

1 It shall not be suggested that turns and messages have identical characteristics: on the contrary, it can be stated that the conditions of time in digital written communication result in completely different practices of interaction management (cf. Beißwenger 2007). 
digital written messages merge into a stream of interactional exchange-be it in the form of consecutive social media postings or text messenger threads (cf. Imo 2015: 25). While each message is oriented to (potentially) sequentially preceding ones, it simultaneously projects the subsequent course of interaction. Interlocutors thus engage in an unfolding social collaboration by semiotic means of writing.

A broad range of studies on computer-mediated communication (CMC), which have been dealing with these phenomena in linguistics for 30 years now (cf. Ferrara et al. 1991; Werry 1996; Runkehl et al. 1998), agree that this novel writing practice goes hand in hand with the usage of specific micro-linguistic structures. While in spoken face-to-face interactions paraverbal and nonverbal signs disambiguate, modify, or emphasize the meaning of verbal contributions, multimodal resources are comparably limited in digital written interaction due to its disembodiment. Although the semiotic repertoire in contemporary online applications is usually extended by pictorial signs such as emojis, stickers, and gifs (cf. Herring and Dainas 2017), written linguistic signs seem to have a clear priority in many of these mediated interactions. ${ }^{2}$ Accordingly, it is the segmental composition of words itself, i. e. spelling, that provides an important realm of contextualization cues (Gumperz 1982) for gaining mutual understanding in digital interactions.

Although the contextualizing function of spelling variation has been mentioned in CMC research for a long time, it is nevertheless remarkable how classifications of spelling variants in digital writing have been rather superficial so far. Regardless of whether studies focused on letter omissions (e. g. <ich komm> instead of <ich komme>), letter substitutions (e.g. <Nain> instead of <Nein>), or letter reduplications (e.g. <schööööön> instead of <schön>), spelling variants were primarily conceptualized in terms of one characteristic: being deviant from spellings in non-interactional standard writing (cf. Danet 2001; Thurlow and Brown 2003; Crystal 2008). While only a few studies explicitly refer to these phenomena as 'wrong spellings', all these different types of spelling variation are nevertheless commonly addressed and therefore homogenized as informal nonstandard spellings'-always implying the 'formal standard' of codified orthography as the relevant point of comparison. As an explanatory factor of variation in digital writing, these traditional approaches highlight an alleged orientation

2 Of course, this hierarchy of modes is in flux and, above all, also tied to genres of digital interaction. Especially with the rising popularity of voice messaging, one might even speak of a new orality that becomes the primary mode of text-messaging in some communities of practice (cf. König and Hector 2019). 
towards speech by interpreting nonstandard spelling variants as an emulation of spoken, mostly prosodic, features. ${ }^{3}$

Even if such a conceptualization states a continuum in which spellings are located as "rather" or "less" nonstandard and/or speech-like, it is worth mentioning that classifications of this kind operate within a bipolar scale, therefore reducing spelling variation to a simple slider between standard and deviating nonstandard. Such a binary perspective not only hides the stylistic agency of interlocutors by implicitly claiming a deterministic connection between text-based CMC and certain micro-linguistic features but also fails to meet the enormous differentiation of communicative practices and social identities that can be cued by spelling variation. Therefore, I suggest, these theoretical shortcomings of a standard-nonstandard dichotomy are to be countered with a more complex view on situated and pluralized writing norms and the formation of these writing norms on the basis of socially shared language ideologies. This approach is not intended to deny standard orthography as an important reference point for digital writing practices but underpins how standard norms are supplemented by local norms to a certain extent (cf. Androutsopoulos 2016). Approaching spelling variation in everyday digital communication needs to take account of these processes of de-binarization.

To this end, my considerations follow the relatively recent tradition of sociolinguistics of writing (Jaffe 2000; Sebba 2007; Lillis 2013) by analytically focusing on spelling in socio-interactional context. I further align myself with such studies that have already taken a metapragmatic, ideology focused approach to phenomena of written language (cf. Debenport and Webster 2019 for an overview). Thus, various scholars have repeatedly pointed out how variational practices of spelling and writing systems take on social values calibrated by the metapragmatic awareness, language ideologies, and socio-cultural ordering of given communities-for example, with a focus on spelling (cf. Androutsopoulos 2000; Jaffe et al. 2012; Screti 2018; Cutler 2020), typography (cf. Spitzmüller 2013; Järlehed 2015), heterographic and bi-scriptural practices (cf. Angermeyer 2005; Neely and Palmer 2009; Spitzmüller 2007), and orthographic standardization (cf. Johnson 2005; Romaine 2005; Donaldson 2017). In these studies, the research interest concerns not only how writing is and becomes the means of socio-communicative practices, but also

3 In Romance Studies and also in German Studies, this speech-oriented conceptualization of digital writing has had a particular career, since it was primarily the model of Koch and Oesterreicher (1985) that was used for theorizing spelling variants as 'conceptually oral'. As a result, many of those spellings that did not match the orthographic standard were often analyzed as 'oral imitations' ex negativo (for a critical review of this tendency see Dürscheid 2003; Androutsopoulos 2007; Albert 2013). 
the other way around, how literacy practices are a driving force in the evolution of writing systems. In this regard, Sebba (2009: 37) states that "a practice account of writing systems is necessary in order to be able to understand how writing systems develop and function within their social context".

To theoretically address the relation between spelling and context, I will first outline the sociolinguistic concepts of linguistic registers and social indexicality in Section 2. This is followed by a discussion on the structural classification of spelling variants in Section 3. In Section 4, these two perspectives on sociocommunicative functions and structural conditions are then brought together in order to outline a research framework for register analysis of digital written interactions. In the following, this framework will be applied in the form of case studies dealing with the digital texting of German adolescents. In Section 5, the underlying data set is presented first, before Section 6 provides a quantitative overview of the occurrence and distribution of spelling variation in the participants' everyday digital writing. The core of the empirical discussion is then built on qualitative sequential analyses in Section 7, which reconstruct the role of codified standard orthography in digital interactions in particular. In addition, following the research framework, Section 8 takes a further look at the reflexive awareness of participants in order to clarify the language ideological foundation of certain variation practices. Finally, Section 9 summarizes central insights and discusses the extent to which a register approach helps to overcome the simplifying binarization of digital writing practice.

\section{Linguistic registers and social indexicality}

Following the assumption that it is less the differentiation of digital media per se than the differentiation of communicative practices enabled by digital media, a de-binarized approach to spelling variation requires a theoretical foundation that focuses primarily on the communicative activities of social communities. I, therefore, propose to apply the sociolinguistic concept of register to phenomena of spelling variation. Register theory describes the interrelation between linguistic variation and contexts of situation (Halliday 1978). While registers have traditionally been conceived of as linguistic varieties whose structures unidirectionally reflect the functional requirements of the situational context (cf. Biber 1994; Biber and Conrad 2009), more interactionally oriented sociolinguistics has recently turned its attention to the understanding of the term as coined by linguistic anthropologists Michael Silverstein (2003) and Asif Agha (2007). In contrast to its functional tradition, this conception of register highlights the stylistic agency of 
speakers who utilize bundles of co-occurrent linguistic forms in order to indicate typified social context and signal that a particular social practice is being performed. Agha (1999) puts it as follows:

A register is a linguistic repertoire that is associated, culture internally, with particular social practices and with persons who engage in such practices. The use of a register conveys to a member of the culture that some typifiable social practice is linked indexically to the current occasion of language use, as part of its context. (Agha 1999: 216)

Accordingly, the approach avoids functional determinism and focuses on the linguistic ideological beliefs and metapragmatic awareness that relate certain linguistic forms to contextual factors from the perspective of speakers. Linguistic forms are investigated for their charging with social indexicality, i.e. how forms become enregistered within a community as pointing to certain properties of social context (Agha 2007; Jaffe 2016). A linguistic form (for example a certain lexical choice) functions as a social indexical when its use indicates a particular sociocontextual quality (for example a communicative stance such as 'being polite', or a particular social identity such as 'being an academic'). Accordingly, a linguistic register is constituted by a co-occurrent set of linguistic forms that are indexically congruent, i.e. pointing to the same property of social context (cf. Agha 2007: 24). For example, the social identity of an 'academic' is not only indicated by a certain choice of lexical items but also by a certain choice of syntactic structures-linguistic features that we accordingly can refer to as components of an 'academic register'. The use of each of these structures may be functionally motivated, but it is also socially enregistered in the metapragmatic awareness of a given population. These enregistered features unfold social indexicality by pointing to the social type of an 'academic' and to certain academic practices as for example 'giving an academic talk'.

A central characteristic of registers is that they are considered contextually appropriate for a certain type of social situation-depending on their indexical enregisterment. From a semiotic perspective, such appropriateness in context can be conceptualized as indexical congruence with preceding contextual signs. For example, a certain educational setting makes the uses of 'academic' forms predictable as indexically congruent. Viewed the other way around, these appropriate forms presuppose properties of social context as already established. In these cases, we observe an “indexical presupposition” (Silverstein 2003: 195). However, the indexical direction in time can also be reversed, in that indexicals point to an emerging property of social context, i.e. establishing new context by an "indexical entailment” (Silverstein 2003: 195). A proper example is the socially meaningful T/V distinction (Tú/Vos) of the second-person personal pronouns in many 
European languages-such as the German distinction between $d u$ and Sie (Brown and Gilman 1960). While in most cases the addressing T-form $d u$ indexically presupposes an informal situation and close social proximity (when, for example, a person of the same age is addressed in a non-professional setting), we can also observe indexically entailing uses in which the T-form does not comply with norms of appropriateness but alters social context (when, for example, the T-form is introduced in a professional setting or a hierarchically superior person is provocatively addressed with the T-form). Evidently, while the register phenomenon in interaction can be considered primarily as a functioning of presupposing indexicals, enregistered (bundles of) forms are also always a resource for indexical entailments. This distinction of "appropriateness-to" and "effectiveness-in" context lies at the heart of social indexicality (Silverstein 2003: 195) and thus also provides a framework of analysis that helps to investigate the empirical usage of registers and single enregistered forms in interactions.

In any case, a precondition of such analyses is the exploration of language ideologies of the community under study: To ensure that the interlocutors can mutually interpret social indexicals in approximately the same way, they are dependent on shared metapragmatic rationalizations, i. e. shared ideas about the appropriateness-to and effectiveness-in-context of perceived register forms. Thus, if we want to know which registers in a population's communicative everyday life are distinguished from each other and perceived as socially meaningful, then we must ethnographically investigate and reconstruct those ideologies, that connect linguistic forms to social values. Besides the structural and interactional analyses of register forms and register usage, the analysis of reflexive awareness of registers must be added as a dimension of sociolinguistic investigation (cf. Silverstein 1985; Androutsopoulos and Busch 2020).

It is also the dimension of reflexive awareness that brings us back to the discussion about the sociolinguistic theorization of digital written communication and the critique of reductionist bi-polar classifications. The perspective on registers as a socio-indexical bundle of forms outlined above seems particularly suitable for modeling the differentiation of communicative practices and the pluralization of writing norms in digital communication. The approach emancipates itself from a simplistic technical determinism (thus rejecting ideas of a homogeneous "Netspeak" [Crystal 2001]) and traces the everyday social activities carried out through the use of writing. This goes hand in hand with a rethinking of the status of the orthographic standard, which is no longer considered the default of any literacy practice per se, but rather a norm among norms-albeit an extremely relevant one-that is part of the societal mosaic of registers of writing. Thus, digital registers of writing do not necessarily form a counterpoint to traditional standard 
orthography, but rather arise by the reflexive awareness of very different communicative practices in different communities. A perceived contrast to the standard language register can sometimes be a relevant part of these metapragmatic perceptions, but not exclusively. Thus, a register approach to digital writing helps to understand how registers are utilized as a communicative resource by the actors (for presupposing and entailing social context), instead of merely stating what these registers are not (i. e. non-interactional standard writing).

\section{Classification of digital spelling variation}

In order to trace these indexical processes analytically, we should first attempt a classification of the semiotic-material basis in the form of structural variants, i.e. spelling variants, in the everyday digital writing of a community under investigation. The range of possible spelling variants is defined by the writing system that is used. If we look at alphabetical writing, the segmental structure of word spellings results in three basic principles of spelling variation: graphemic substitution, graphemic expansion, and graphemic reduction. All these three principles can be considered productive writing strategies of digital communication in view of the relevant linguistic CMC literature that reports spellings such as $<$ leude $>$ instead of $<$ Leute $>$ (graphemic substitution), $<$ cooool $>$ instead of $<$ cool $>$ (graphemic expansion), and $<\mathrm{cu}>$ instead of $<$ see you $>$ (graphemic reduction) (cf. Danet 2001; Tophinke 2002; Thurlow and Brown 2003; Shortis 2007; McSweeney 2018).

Furthermore, the spelling variants of each category are distinguished fundamentally by the fact whether they appear phonically motivated or not. Therefore, on a second axis we can differentiate between phonostylistic spellings and graphostylistic spellings (cf. Androutsopoulos and Busch 2020: 17; see Table 1). Graphostylistic variation is characterized by the fact that variants of its paradigm are homophone, making use of one-to-many phoneme-to-grapheme correspondences. Examples include graphemic substitutions such as <boyz instead of $\langle$ boys $\rangle$, rebuses such as $\langle\mathrm{u}\rangle$ instead of $\langle$ you $\rangle$, but also the allographic use of special characters such as <@rbeiten> instead of <arbeiten> (cf. Androutsopoulos 2000: 521-522). The perceptible difference between these variants, which is the structural prerequisite of social indexicality, is thus purely graphic-visual here. It is noteworthy that orthographically licensed variation usually falls within the realm of graphostylistic spellings-for example variation of $\langle\mathrm{ph}\rangle$ and $\langle\mathrm{f}\rangle$ in German orthography such as in <graphisch $>$ and $<$ grafisch $>$, or the variation of suffix <ise> and <ize> between British and American English (cf. Sebba 2009: 38). 
Table 1: Classification of digital spelling variation.

\begin{tabular}{|c|c|c|}
\hline & graphostylistic spellings & phonostylistic spellings \\
\hline substitution & $\begin{array}{l}\text { homophone substitution } \\
\text { (e.g. }\langle\text { boys }\rangle \mid\langle\text { boyz }\rangle)\end{array}$ & $\begin{array}{l}\text { heterophone substitution } \\
\text { (e.g. }\langle\text { Hamburg }\rangle /\langle\text { Hamburch }\rangle \text { ) }\end{array}$ \\
\hline expansion & 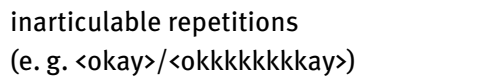 & $\begin{array}{l}\text { articulable repetitions } \\
\text { (e. g. }\langle 0 k a y>/<0000000000 k a y\rangle\end{array}$ \\
\hline reduction & $\begin{array}{l}\text { inarticulable omissions/abbreviations } \\
\text { (e. g. }\langle\text { vielleicht }\rangle /\langle v l l t\rangle)\end{array}$ & $\begin{array}{l}\text { articulable omissions/abbreviations } \\
\text { (e. g. }\langle\text { komme }>/\langle\text { komm }\rangle \text { ) }\end{array}$ \\
\hline
\end{tabular}

In contrast, phonostylistic spellings represent certain phonetic distinctions, which in turn unfold socio-indexical potentials. Phonostylistic variants can be further subdivided according to whether they represent a supra-regional characteristic of colloquial spoken language (for example certain elisions such as $<$ komm $>$ instead of $<$ komme $>$ or contractions such as $<$ machs $>$ instead of $<$ mach es>) or whether they transcribe a certain regiolectal or otherwise socially significant feature of pronunciation (for example North German spirantizations such as $<$ Hamburch $>$ instead of $<$ Hamburg $>$ or coronalizations such as $<$ isch $>$ instead of $<\mathrm{ich}>$ ). Certainly, we could argue whether such cases fall into the realm of spelling variation at all or whether they are instances of phonetic-phonological variation, which are represented graphically only on a subsequent secondary level. However, from a theoretical perspective that emphasizes the autonomy of writing (cf. Neef and Primus 2001), it should be pointed out that a linguistic item such as $<$ Hamburch $>$ is a written and not a spoken form and that the relevant variation, therefore, does not concern the sounds [k] and [ç] but the letters $\langle\mathrm{g}\rangle$ and $\langle\mathrm{ch}\rangle$.

Another important aspect is that the classification shown in Table 1 does not operate based on decontextualized forms (unlike the brief examples might suggest at first) but on the basis of forms in use, i. e. communicative practice: The notion of grapho- and phonostylistic spelling implies that writers intentionally use forms to indicate a certain appropriateness-to or effectiveness-in-context by the stylistic value of the form. In other words: these spellings unfold social indexicality from the writer's perspective.

However, this leaves out an important category of spellings, to which the writer's intention is at least doubtful: typos (e. g. transpositions such as $<$ udn $>$ instead of $<$ und $>$ ) and misspellings (e. g. substitutions such as $<$ Hamburk $>$ instead of $\langle$ Hamburg $\rangle$ ) that could also be formally understood as graphemic substitutions but do not serve any communicative intent (cf. McSweeney 2018: 28). While stylistic spellings can be considered "functional, principled and meaningful" (Tagg et al. 2012: 369), typos and misspellings are defined ex negativo-these 
forms unfold social indexicality only from the readers' perspective and are interpreted (rightly or wrongly) as unintentional.

What can be understood intuitively as a relatively clear categorization encounters an enormous problem in analytical practice: the operationalization of intentionality. As a cognitive factor, intention is not accessible by the analysis of semiotic material actions. Instead, it is necessary to clarify the communicative assumption of intentionality as a metapragmatic action (cf. Jaffe 2000: 49; Spitzmüller 2013: 202). Those forms are analytically classified as 'intentional' that are treated as 'intentional' by the local co-participants in the course of interaction. Thus, to analyze assumptions of intentionality, a focus on cooccurring indexicals (especially other spellings) is required. If these are in a congruent relationship of indexical presupposition, then the form in question seems to be perceived as a stylistic spelling. For example, a graphemic substitution such as <Hamburch $>$ instead of <Hamburg $>$ can be assumed to be stylistically intended when other cooccurring forms display a socially indexical congruence, for example by also pointing to a social value of 'North Germanness' or connotatively related sociocultural concepts. A spelling such as $<$ Hamburk $>$, in contrast, cannot unfold such social-cultural indexicality, but probably only indicates the class of misspellings in which the final obstruent devoicing is represented graphically (contrary to the morphemic principle of German orthography, which demands the graphemic representation of the voiced obstruent in the form of $\langle$ Hamburg $\rangle$ ). However, this does not exclude the possibility of a writer intentionally wanting to display this type of misspelling, for example, for reasons of ironic stylization. Hence, digital spelling analysis must always take into account the interactional and semiotic context of forms under investigation.

\section{Framework for register analysis of digital written interactions}

Following on from this, register analysis focusing on digital writing can be outlined as a tripartite framework focusing on the interrelation of I) spelling variants, II) communicative practice, and III) reflexive awareness (cf. Androutsopoulos and Busch 2021). Therefore, it is a reasonable first step to measure the occurrence and distribution of spelling variants in a suitable sample of the social population under investigation. Counting relative frequencies of writing variants in a sample offers a first quantitative overview of which variants are relevant for certain literacy domains within a given community. The analysis can be based on the predefined structural categories of spelling variation as seen in Table 1, but may also 
include finer categories (for example, the category of phonostylistic reductions might be further distinguished according to whether elisions or contractions are represented, etc.). Furthermore, it is useful to make comparisons, i. e. to specify frequencies of spelling variants in relation to another text sample (cf. Biber and Conrad 2009: 36). For example, it could be examined whether graphemic substitutions are more frequently observed in non-institutional text messaging or in institutional e-mail communication of a given population, etc.

After identifying the distributional characteristics of spellings within a sample, a qualitative analysis of forms in context, i. e. communicative practice, can draw a more detailed picture. On the one hand, it might be interesting to look at the use of very rare exceptional spellings in detail, on the other hand, those spellings that are used very often are of particular interest. The analysis can show what functional conditions may favor these frequent spellings and what social indexicalities can be traced in the data. Thereby analytically attention has to be paid to what extent spelling variants become evident as presupposing indexicals that belong to a register norm. Especially those spellings that appear particularly frequently and regularly in certain contexts are candidates to represent the communicative default, i. e. the unmarked stylistic choice. This can then be verified by analyzing the form in context. Here, the method of sequential analysis is particularly suitable, as it is known from conversation analysis (Schegloff 2007), interactional linguistics (Couper-Kuhlen and Selting 2018), and interactional sociolinguistics (Gumperz 1982), and has also been successfully applied to written interactions in digital media (cf. Beißwenger 2007; Giles et al. 2015; Imo 2015; Pappert 2017). By examining the sequential progression of a written message thread and the interactional elaboration of topic, stance, and displayed context in general, the indexical portion of a spelling variant can be analytically assessed. By sequential analyses, it is also possible to reconstruct whether a spelling practice rather unfolds entailing indexicality. The goal of qualitative analysis is thus clearly defined: On the one hand, we are looking for local registers of writing manifested by socially congruent spelling variants that are considered appropriate for a certain communicative practice within a given community. On the other hand, we reconstruct how interlocutors shape and alter interactional contexts through socially enregistered forms.

The analysis of communicative practice is thus dedicated to socially enregistered spellings in action and shows which local indexicality governs the communicative context of a written utterance. In order to underpin the analysis of these local and emergent indexicalities, however, it is worth taking a complementary look at the typified, translocal enregisterments of the forms under investigation, as manifested in articulated reflexive awareness. Through the analysis 
of metapragmatic utterances-as it is known from research on language ideologies (cf. Silverstein 1979; Irvine and Gal 2000)-it is possible to trace the nuances of indexical meaning that a particular spelling variant might potentially unfold within and for a social population (cf. Eckert 2008). Such metapragmatic data can be collected from everyday interactions, public media discourses, or can also be elicited through interviews or other ethnographic methods. In any case, such data help to understand the socio-cultural charges of certain forms and the underlying perceptions, conceptualizations, and rationalizations of linguistic and social difference from the perspective of language users. The focus on reflexive awareness thus provides important background for the interpretation of sequential analyses.

In the following, I will illustrate how spelling variants, communicative practice, and reflexive awareness constitute three axes of exploration that enable the holistic description of registers of digital writing. Case studies from the everyday literacy of North German adolescents will be discussed to demonstrate the interplay of these three phenomenological and methodological levels.

\section{Data}

The following investigations are based on data collected as part of a doctoral project on digital registers of writing in Northern Germany (cf. Busch 2021a). 23 participants between the age of 13 and 18 provided text portfolios, each consisting of at least two text-messaging logfiles (exported directly from the WhatsApp application) as well as at least three school essays for comparison. The data collection resulted in a WhatsApp subset of 18,802 messages with 151,970 word tokens ${ }^{4}$ and a school essay subset of 77 texts with a total of 22,920 word tokens. Both subsets are monolingual German data (with minor exceptions). While the school sample consists mainly of essays from German literature classes (i. e. formal educational writing), the WhatsApp threads represent informal communication between friends. Accordingly, typical communicative practices of the WhatsApp sample are arranging appointments, doing small talk, gossiping, and joking in the context of the participants' everyday social life, which revolves around the school. In addition, 16 of the participants were also willing to participate in seven group interviews in which they were confronted with authentic stimuli from the

4 The count only refers to the contributions of the 23 participants and not to the respective chat partners. Including the complementary contributions results in an extended WhatsApp sample of 301,987 word tokens in total. 
WhatsApp subset in order to elicit metapragmatic discourse. The focus here was on the general language ideological assumptions and rationalizations of the participants but also on the social enregisterments of specific spelling variants from the participants' point of view.

Based on this data, the three levels of the register analysis are demonstrated below. Section 6 first gives an insight into the distribution of spelling variants, followed by exemplary sequential analyses of phono- and graphostylistic spellings in Section 7, which are then linked back to the reflexive awareness of the participants in Section 8.

\section{Distribution of spelling variants in adolescents' digital writing}

Table 2 shows selected variable categories that have been manually annotated in both the school essay subset and the WhatsApp subset. Each of these annotations marks a selective process in which a writer has decided to encode a word into a certain graphic form, within the scope of the possibilities afforded by the German writing system. Furthermore, each annotation was done with respect to the interactional context-i. e., each annotated spelling was evaluated in terms of whether it was interpreted as intentional by the participants.

This annotation process naturally faces tension between theoretical claim and methodological application: On the one hand, the analysis aims at theoretically acknowledging spelling variants beyond reductive binarity. On the other hand, precisely those forms that do not comply with the orthographic standard are annotated. Here it is practically impossible to avoid the standard as a point of comparison. It is therefore all the more important to stress that this methodic focus on 'norm deviation' is only a heuristic tool (cf. Spiller 2004: 211). However, the results in Table 2 show that the codified norm of orthography may well represent an approximation of metapragmatic norms that a population maintains for a particular communicative area: School essay spellings largely conform to the codified norm, resulting in frequencies around zero-while the categories of variation examined are more frequently annotated in the WhatsApp subset.

Particular spellings turn out to be typical for informal writing on WhatsApp. This can be seen most clearly in the category of phonostylistic elisions. While 10.7 phono-stylistic elisions per 1,000 word tokens occur in the WhatsApp subset, similar spellings in the school subset have a frequency of only 1.4 per 1,000 word to- 
Table 2: Distribution of spelling variants in the school and WhatsApp sample. (Normalized results, divided by the total number of word tokens per subset, multiplied by 1,000 and rounded. Absolute numbers in brackets.)

\begin{tabular}{|c|c|c|c|}
\hline & examples & school essays & WhatsApp chat logs \\
\hline phonostylistic elision & $\langle i c h$ komm〉, 〈is〉 & $1.4(33)$ & $10.7(1,629)$ \\
\hline phonostylistic contraction & $\langle$ gehts $\rangle,\langle$ isso $\rangle$ & $0.2(4)$ & $1.4(223)$ \\
\hline phonostylistic substitution & $\langle$ Dankö〉, 〈wat $\rangle$ & $0(0)$ & $0.6(87)$ \\
\hline graphostylistic substitution & 〈NAIN>, 〈@rbeiten> & $0(0)$ & $0.8(113)$ \\
\hline letter reduplication & 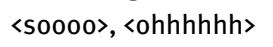 & $0(0)$ & $4.6(692)$ \\
\hline capitalization & $\langle$ FERTIGKUCHEN〉 & $0.8(18)$ & $1.1(164)$ \\
\hline $\begin{array}{l}\text { lowercase nouns and proper } \\
\text { names }\end{array}$ & $\langle$ radio〉, 〈anne〉 & $7.4(169)$ & $22.4(3,410)$ \\
\hline
\end{tabular}

kens. Especially common in this category are $e$-elisions of verb forms of the first person singular. ${ }^{5}$ For example, the reduced verb form $\langle$ hab $>$ as opposed to the orthographically licensed full form <habe $>$ is marginally used in the school essays but is the most common variant in the WhatsApp subset. We find that 19 of the 23 participants use the reduced form with a relatively higher frequency than the full form. Obviously, phonographic reductions of the schwa representation <e > fit in with the normative expectations in the digital writing of these individuals. Thus, realizations of reduced spellings such as $<$ hab $>$ are not deviations here. They tie in with the informal context of digital interactions as indexically presuppositions and prove to be the default variants in WhatsApp texting. In contrast, the few instances of $e$-elisions in school essays have an opposite indexical status. The forms do not relate to a given context but create a new contextual quality by being used primarily in direct speech of narrated characters. Phonostylistic elisions are thus used in school writing as a means of stylizing orality and spontaneity, i. e. constituting indexical entailments, but do not belong to the register default of educational school writing.

Similar dynamics can be observed also for other dimensions of spelling variation. For example, the WhatsApp subset contains relatively frequent lowercase nouns and proper names (22.4 per 1,000 word tokens), which cannot be adequately classified as non-orthographic misspellings, since the participants certainly display relevant orthographic rule awareness in their school texts. Instead, the continuous lowercase letters must also be understood as presupposing in-

5 A central result of linguistic CMC research on German chats and texting is thus reproduced here (cf. Runkehl et al. 1998: 102; Schnitzer 2012: 98). 
dexicals that are interpreted as appropriate in the context of informal writing via digital media (and linguistic ideologically rationalized as, for example, a result of fast writing-to preface the dimension of reflexive awareness here). Consequently, in the population under investigation, constant lower case belongs to the unmarked default of the digital register of informal writing.

Such examples suggest the extent to which frequencies and social indexicality interrelate. High numbers indicate those categories of structural variation in which certain spellings are realized recurrently. These spellings, in turn, are potential candidates that may have been established as contextually appropriate forms in digital interactions of the population under study. They form a linguistic ideologically normalized default, i. e. belong to a contextually appropriate register. In contrast, we see other spelling variants that are less frequently used. Phonostylistic substitution, for example, umlaut spellings such as <Dankö> (instead of $<$ Danke $>$ 'thanks'), and also graphostylistic substitutions, for example, rebuses such as <@rbeiten> (instead of < arbeiten> 'to work'), are documented in the WhatsApp subset but are marginal in terms of frequency (see Table 2). It seems that it is precisely these isolated moments of spelling variation that allow us to understand the contextualizing effects of graphemic selection and how it indexically alters communicative stances and social identities in interaction. In order to not only detect these socio-indexical effects within the dataset but to describe and explain them in detail, a qualitative analysis of the sequential environment is the next step to do.

\section{Spelling variation as communicative practice in WhatsApp interactions}

The following case studies will focus on indexical entailments of digital spellings in interaction. In particular, the selection of examples is intended to demonstrate the versatile, relative status of standard orthography in digital writing practices. On the one hand, I will discuss phonostylistic substitutions in Section 7.1, on the other hand, I will discuss graphostylistic substitutions in Section 7.2. Both categories of variation are exceptional in terms of frequency in the subset (with less than 1 instance per 1,000 word tokens), but for this very reason, they are powerful interactional resources, whose communicative effects and metapragmatic appropriation we can examine particularly well. 


\subsection{Phonostylistic substitution in interaction}

A suitable example to illustrate the interactional practice of phonostylistic substitution is found in an appointment sequence between 15-year-old participant Tobias and his buddy Timm.

Example 1: Organizing hangouts (chat log TOB-W1, translation in italics).

\begin{tabular}{|c|c|c|c|}
\hline 01 & 13:56: & Timm: & $\begin{array}{l}\text { Wollen wir heute was .achen, } \\
\text { Want to hang out today, }\end{array}$ \\
\hline 02 & 13:56: & Timm: & $\begin{array}{l}? \\
?\end{array}$ \\
\hline 03 & 14:06: & Tobias: & $\begin{array}{l}\text { Ich weiß nicht ob ich kann:/ } \\
\text { Don't know if I have time:/ }\end{array}$ \\
\hline 04 & 14:06: & Tobias: & $\begin{array}{l}\text { Wenn ich kann dann erst später gegen } 5 \\
\text { If I have time then later around } 5\end{array}$ \\
\hline 05 & 14:06: & Timm: & $\begin{array}{l}\text { Ich ruf dich auf jeden Fall noch an oder schreib dir boy } \\
\text { In any case I will call or text you boy }\end{array}$ \\
\hline 06 & 14:12: & Tobias: & $\begin{array}{l}\text { Jaoke } \\
\text { All right }\end{array}$ \\
\hline 07 & 14:12: & Tobias: & $\begin{array}{l}\text { Ich kann aber auch eh erst dann so } \\
\text { It also suits me only later anyway }\end{array}$ \\
\hline 08 & 14:13: & Timm: & $\begin{array}{l}\text { Ja gut } \\
\text { All right }\end{array}$ \\
\hline 09 & 17:23: & Tobias: & $\begin{array}{l}\text { Dennsach bescheid minjunv } \\
\text { Then let me know my boy }\end{array}$ \\
\hline 10 & 17:35: & Timm: & $\begin{array}{l}\text { Man ich kann nicht } \\
\text { Damn I have no time }\end{array}$ \\
\hline 11 & 17:35: & Timm: & $\begin{array}{l}\text { Sorry dude } \\
\text { Sorry dude }\end{array}$ \\
\hline
\end{tabular}

For our discussion especially message 09 is striking. Here, Tobias uses several spelling variants that are socially enregistered as 'North German': the temporal adverb <denn> (instead of standard German dann), the spirant ending of the verbal imperative $<\mathrm{sach}>$ (instead of standard German plosive sag), and the formulaic noun phrase <min Jung $>$, that incorporates monophthongization of mein and an $e$-elision of Junge (albeit with a typo where the adjacent keys of $\langle\mathrm{g}\rangle$ and $\langle\mathrm{v}\rangle$ were confused). The message shows how Tobias combines indexically congruent variants of 'North Germanness' to achieve a communicative effect in context. These indexically entailing variation phenomena are especially remarkable because Tobias' previous messages on the contrary contain presupposing indexical phonostylistic forms (e.g., the $e$-elisions of 1st person singular verbs $<$ ruf $>$ 
and <schreib> in message 05), but no regionally enregistered forms. In Tobias' message 07 , there is even a realization of the temporal adverb $<$ dann $>$, which contrasts directly with < denn $>$ in message 09 . This makes it very clear: The spelling variants in message 09 are indexically distinct and must therefore be considered with respect to their contextualizing function within the broader interactional sequence.

In message 04, Tobias states that he would have time for a meeting at about 5 p. m., followed by message 05 in which Timm announces that he would contact Tobias again for a final appointment. After the targeted time has already been exceeded by 23 minutes without Timm having texted, Tobias sends the phonostylistically striking message 09 . The follow-up request has face threatening potential by addressing the broken agreement and imperatively referring to Timm's future actions (let me know). Therefore, the fact that this imperative utterance is realized with a 'North German' voice seems to be due to politeness strategy and social relationship management. In line with current research on language attitudes, it can be observed here how the "covert prestige" of North German nonstandard forms is used for social positioning (cf. Schröder 2015: 49). By following Blom and Gumperz (1972), message 09 can be classified as metaphorical codeswitching in order to contextualize Tobias' message as friendly or, more appropriately, 'buddylike'-mitigating the face-threatening potential. The context indexically entailed here is therefore that of a straightforward but warm North German friendliness. ${ }^{6}$

In any case, it is evident that Tobias' texting is not realized as a continuous regiolectal or dialectal writing (as we know it from Swiss-German WhatsApp communication, for example, cf. Siebenhaar 2020), but rather includes selective indexical entailments using a limited pool of socially enregistered regiolectal spelling variants. The case study thus shows an important issue: Of course, the 'buddy-like' spelling style derives its social indexicality from its perceived difference to other forms-but this difference concerns less the codified standard of orthography, but rather the local default of presupposing indexicals, i. e. the informal register of digital writing.

6 Remarkably, this indexing of friendliness runs through Tobias' and Timm's WhatsApp thread and is not only achieved by spelling variants of 'North Germanness', but also by (American) English forms such as boy, dude, bro and bra, whose function for maintaining heterosexual male friendships has already been described sociolinguistically (cf. Kiesling 2004). Two of these forms can also be found in the examined sequence: Tobias is addressed as boy in message 05, and as dude in message 11 in the course of the apologetic rejection. The North German addressing phrase min Jung (my boy) fits into these propositions of masculinity. 


\subsection{Graphostylistic substitution in interaction}

The fluid social value of the orthographic standard is also evident in the communicative practices of graphostylistic variation. In the following, I will present the case study of 17-year-old Frank, which is then contoured in Section 8 by the reflexive awareness of the same participant. While the phonostylistic substitutions in Section 7.1 operated more in relation to an informal, local norm beyond the standard, the following example from a WhatsApp thread of Frank with his friend Martin illustrates how the orthographic standard and its linguistic ideological hegemonic position can also be an important reference point in digital writing. For this, Example 2 is particularly illuminating, because it is explicitly metalinguistic.

Example 2: Being ungrammatical (chat log FRA-W2, translation in italics).

\begin{tabular}{|c|c|c|c|}
\hline 01 & 14:03: & Frank: & $\begin{array}{l}\text { Tag. Singular Plural alles nebensächlich... } \\
\text { Hello. Singular plural everything's irrelevant }\end{array}$ \\
\hline 02 & 14:03: & Martin: & $\begin{array}{l}\text { Aufjedenfall } \\
\text { Absolutely }\end{array}$ \\
\hline 03 & 14:04: & Frank: & $\begin{array}{l}\text { Jo wer brauchen schon Grammatisch? } \\
\text { Yo who need grammatical? }\end{array}$ \\
\hline 04 & 14:04: & Martin: & $\begin{array}{l}\text { Kein Ahnung grammatik du } \\
\text { No idea grammar do you }\end{array}$ \\
\hline 05 & 14:05: & Frank & $\begin{array}{l}\text { Jop. Hap vidio sehen. } \\
\text { Yop. I've seen video. }\end{array}$ \\
\hline
\end{tabular}

The inducement for the short sequence cannot be reconstructed from the preceding Whats App thread and must lie in an external experience of Frank and Martin. The brief interactional context is nevertheless sufficient to draw our attention especially to message 05 , which contains two interesting instances of graphemic substitution: First, we observe the form <hap>, which, as the first-person singular of haben (standard variant: 〈habe>), not only incorporates a phonostilistic $e$-elision but also violates the morphemic principle of German orthography by using $\langle\mathrm{p}\rangle$ instead of $\langle\mathrm{b}\rangle$. Although voiced plosives are fortified at the end of words in German pronunciation and thus the pronunciation ['hap] complies with the spoken standard, German standard orthography demands morphological constancy and thus the letter $\langle\mathrm{b}\rangle$ at the word ending. The second remarkable spelling $\langle$ vidio $>$ can also be traced back to a spoken-language phenomenon, namely the spoken /e/-raising from ['viddeo] to ['vi:dio], which is not to be represented in standard orthography. $<$ Video $>$ is the only orthographically licensed spelling variant. 
Although both spellings, as overrepresentations of pronunciation, initially appear like typical misspellings, they have been analyzed as graphostylistic forms-or more precisely: as stylizations of misspellings. The forms fit into an interactional context, in that grammatical 'correctness' is not only expressed meta-linguistically on a propositional level but is also staged through a series of other features, especially the simplification of syntax and suffixes, by both Frank and Martin. In message 03, for example, Frank realizes an infinitive construction reminiscent of foreigner talk, ${ }^{7}$ and Martin omits the preposition of the prepositional phrase < [von] grammatik $>$ in message 04, apparently also with the intention of stylizing deficient German. Accordingly, in message 05, we see how the distinction between misspelling and graphostylistic spelling is not a formal one but is based on metapragmatic attributions that result from the reflexivity of the contextual surroundings for both participants and analysts. Here, these stylizations of stereotypical misspellings indicate a double voicing (cf. Bakhtin 1986; Hill 1993), which indexically entails the abstract social persona of an 'incompetent writer' to whom Frank takes a distancing and-most importantly-socially superior stance. Here, the social status of standard orthography is thus made clear precisely by its stylized absence.

The fact that Frank, in particular, tends to stigmatize misspellings and at the same time is committed to a rather conservative prestige of orthography is also shown by a second graphostylistic phenomenon that cuts across his WhatsApp threads: Frank is the only participant who spells $<$ daß $>$ instead of $<$ dass $>$, as for example in message 03 of the following sequence.

Example 3: $\langle ß\rangle$ in interaction (chat log FRA-W2, translation in italics).

\begin{tabular}{|c|c|c|c|}
\hline \multirow[t]{2}{*}{01} & 15:40: & Martin: & $\begin{array}{l}\text { Willst du heute abend mit mir arne einem tom und einem jannis } \\
\text { minecraft zocken? }\end{array}$ \\
\hline & & & Do you want to play minecraft with me arne tom and jannis tonight? \\
\hline \multirow[t]{2}{*}{02} & 16:43: & Martin: & Achso ja kannst ja nicht \\
\hline & & & Oh well you don't have time \\
\hline 03 & 20:13: & Frank & $\begin{array}{l}\text { Danke, daß du fragst. Aber nicht so gern. Grüß von mir:) } \\
\text { Thank you for asking. But not so much. Greetings from me:) }\end{array}$ \\
\hline
\end{tabular}

7 The verb form < brauchen $>$ may possibly also be analyzed as a contraction of 3rd person singular $\operatorname{brauch}(t)+$ modal particle denn. Then the form would fit more into the stylization of an overgeneralized phonographic principle of spelling. I thank the anonymous reviewer for this suggestion. 
Frank's graphemic choice seems remarkable anachronistic since in the course of the German spelling reform in 1996, the spelling of the subjunction <daß> was replaced by <dass> as the only licensed standard variant-eight years before Frank's written language acquisition began in elementary school. Nevertheless, in Frank's chat logs, <dass $>$ is found 6 times, while $<$ daß $>$ can be observed 9 times.

It seems less plausible to analyze these spellings as stylized orthographic incompetence as in the example above or even as non-intentional misspellings. Rather, the form must be explored against the backdrop of the social enregisterment of the letter $<ß>$ in general and the variant $<$ daß $>$ in particular in the course of the public metalinguistic discourse surrounding the German spelling reform (cf. Johnson 2005). Spitzmüller (2012: 262) traces how the letter $<\beta>$ became a social emblem for the reform's critics: The letter underwent a language ideological iconization and thus served its writers as a social index of their (linguistically) conservative attitude. The subjunction $<$ daß $>$ had particular relevance in this process since it was most often referred to as an example of pre-reform spellings in public meta-discourse (cf. Stenschke 2005: 177).

Given its discursive special position, it is not surprising that the variant $\langle\mathrm{da} \beta\rangle$ is the only feature of pre-reform German spelling in Frank's texting. Other words, which were spelled with $\langle\beta>$ according to the old German orthography (for example $<$ Schluß $>$ or $<$ bißchen $>$ ), are consistently spelled with $<$ ss $>$ by Frank-sometimes in close contextual proximity of a $<$ daß $>$ spelling. Unlike the socially salient $<$ daß>, these spellings do not unfold the indexicality that would make them useful as a means of social positioning.

But what kind of social position is displayed here? Certainly, Frank's <daß> variants are no political statement against the German spelling reform of 1996. However, the choice of the variant does indicate Frank's linguistically conservative orientation, which is also indexed elsewhere-for example at the level of punctuation (Frank is one of the few users of periods and commas in the WhatsApp subset, cf. Androutsopoulos and Busch 2021; Busch 2021b) and at the level of pictograms (Frank tends to use old emoticons $<$ :) > rather than the new emojis $<$ (-) $>$ ). In this respect, the graphostylistic spelling $<$ daß $>$ is only one feature in a bundle of indexically congruent forms with which Frank indicates his linguistic conservatism. What seems remarkable about Frank's spelling $<$ daß $>$ is that it illustrates how graphemic substitutions do not per se indicate a subversive stance toward orthographic regulation. In fact, Frank's <daß> seems to be more of a social index of an elitist 'super-orthographic' stance from which Example 2 is also explained. 


\section{Frank's reflexive awareness of spelling variation}

The metapragmatic analysis of Section 7.2 becomes particularly plausible by including interview data with Frank. In comparison to other interview participants of the same study, who reflect on addressees as clearly the most important contextual dimension of choosing appropriate spellings (i. e. indexical presuppositions), Frank explicitly rejects any orientation to addressees at all. When I asked if it would play any role for his spelling who would later read what he wrote, Frank replied: "No. What is more important to me is what the person who reads it assumes and thinks about me. That is more important than who reads it." 8

Frank's central concern here is that his own social positioning construed indexically through spelling is valid across contexts. He always wants to "simply write as well as I can". ${ }^{9}$ Thereby, Frank reflects on his 'own' spelling style with a translocal claim: He negates situated spelling styles and proclaims a decontextualized 'proper writing'. As becomes clear in the further course of the interview, Frank characterizes the social persona indexically entailed by his 'proper' spellings as being "educated" and not belonging to the "mainstream" group of texting teenagers. Thus, Frank's metapragmatic positioning does not only achieve affirmative adequation but also social distinction from a stereotypical social group (cf. Bucholtz and Hall 2005). When Frank uses <daß> instead of $<$ dass > or emoticons instead of emojis, he focuses on the differences in relation to the linguistic "trends" that he perceives among his peers and judges negatively as "superficial". Instead of joining, he indexes his 'own' distancing social position.

The fact that some of his distinctive forms are not part of the contemporary codified German orthography (such as $\langle$ daß $\rangle$, but also non-codified emoticons) shows that Frank does not primarily urge for standard spellings per se but rather focuses on social distinction from 'mainstream' nonstandard spellings. For this, Frank constructs some sort of 'counter register', as it were, which he rationalizes metapragmatically from a culturally pessimistic position. In the later course of the interview, when asked how his spelling changed after he got a smartphone, Frank answered: "Well, I would say that social media writing has changed my spelling in that I make an extra effort to be a bit more conservative in the way I write."10

8 Original: „Nein. Eher, was die Person, die’s liest dann von mir annimmt und über mich denkt. Das ist wichtiger als wer's liest.“

9 Original: „Ich würde einfach so gut schreiben, wie ich kann.“

10 Original: „Also ich würde jetzt sagen, dass das Schreiben in den Sozialen Medien mein Schreiben in dem verändert hat, dass ich mich anstrenge, ein bisschen konservativer zu sein, in dem, wie ich schreibe.“ 


\section{Conclusions}

In this paper, I have analyzed to what extent spelling variation can be observed as communicative practice in everyday digital interactions. Starting from a theoretical perspective on processes of pluralization in digital written communication, I discussed spelling variation in interaction through the analytical lens of social indexicality-a concept rooted in linguistic anthropology and interactional sociolinguistics. In particular, the Silversteinian distinction between indexical presuppositions and indexical entailments proved to be a useful tool not only on a theoretical but also on an empirical level. Socially enregistered spelling variants are to be understood as indexicals, which in local contexts are either considered appropriate to expectational norms (i.e. belong to a socially shared register of writing) or shape and alter novel contextual properties (i. e. being perceived as socially meaningful stylistic choices). By focusing on local metapragmatics, the approach opens the view to plural indexical differentiations based on language ideologies and therefore overcomes simplifying standard/nonstandard dichotomies.

Moreover, the paper focused on the structural conditions of socially meaningful variation: Since perceivable differentiation is the prerequisite for social indexicality, the structural classification of spelling variants must play an important role in addition to a sociolinguistic foundation. To this end, the paper proposed a classification of spellings depending on whether a variant is a graphemic substitution, extension, or reduction, and whether its alternation is derived from spoken language or graphically autonomous visual modulation. These categories outline the range in which digital spelling forms vary, thus constituting socially meaningful indexicals in context. Subsequently, a tripartite research framework was presented that combines the structural and socio-communicative perspectives: The first analytical dimension deals with the distribution of structural variants, the second dimension investigates the functions of these variants in communicative practice, and finally the third dimension reconstructs the participants' reflexive awareness of these practices in order to achieve a holistic understanding of spelling variation in interaction.

This research program was then exemplified with case studies that focused on the ambivalent metapragmatic status of standard orthography in the digital texting of German adolescents. On the one hand, it was shown that forms that must be considered 'nonstandard' in terms of the codified standard orthography comply with the local norm of an informal register of writing in the social population under investigation. In particular, phonostylistic reductions, such as $e$-elisions, proved to be characteristic of digital everyday texting and constitute a metaprag- 
matic default in these communicative situations. Accordingly, it turned out that communicative practices that are supposed to unfold a particular indexical effect in context, for example for the purpose of politeness, primarily display distinction from the local norm rather than the codified norm. This may even go so far that orthographically licensed variants can be used as stylistically marked, for example, to indicate socio-emotional distance. Especially with Frank, it became evident that the so-called 'nonstandard' itself can be counteracted by parodically stylized misspellings, or by realizing conservative forms, such as the variant $\langle$ daß $\rangle$, that are used to position oneself socially as 'intellectually superior'. Although Frank's pronounced linguistic conservatism is certainly an exception in the population under investigation, these case studies illustrate the fundamental dynamics between competing metapragmatic norms and the resulting indexical potentials. Instead of a binary distinction between standard and nonstandard, we can observe variational paradigms such as $\langle$ habe $\rangle$, $\langle$ hab $\rangle$, and $\langle$ hap $\rangle$, which may suggest different indexical readings depending on their interactional context.

Given this flexibility of spelling practice, future research has the task of further elaborating on the relationship between structural variation and socioindexical potential. Although it is becoming apparent that phonostylistic variants in particular (based on solidified social enregisterments of spoken linguistic features) tend to manifest indexical presuppositions primarily, it remains uncertain whether there are certain formal conditions for contextually appropriate or effective spelling variants. In any case: Tracing these spelling phenomena inevitably means taking a look at the language ideological foundations of their social indexicalities. In this sense, the investigation of digital spelling variation in interaction is always an interdisciplinary matter, in which sociolinguistics of writing and research on writing systems go hand in hand.

Acknowledgments: I am grateful to the editors of this special issue as well as to the two anonymous reviewers for exceptionally constructive reviews.

\section{References}

Agha, Asif. 1999. Register. Journal of Linguistic Anthropology 9(1-2). 216-219. Agha, Asif. 2007. Language and social relations. Cambridge: Cambridge University. Albert, Georg. 2013. Innovative Schriftlichkeit in digitalen Texten. Syntaktische Variation und stilistische Differenzierung in Chat und Forum. Berlin: Akademie Verlag.

Androutsopoulos, Jannis. 2000. Non-standard spelling in media texts. The case of German fanzines. Journal of Sociolinguistics 4(4). 514-533. 
Androutsopoulos, Jannis. 2007. Neue Medien - neue Schriftlichkeit? Mitteilungen des Deutschen Germanistenverbandes 1(7). 72-97.

Androutsopoulos, Jannis. 2016. Theorizing media, mediation and mediatization. In Nikolas Coupland (ed.), Sociolinguistics. Theoretical debates, 282-302. Cambridge: Cambridge University.

Androutsopoulos, Jannis \& Florian Busch. 2020. Register des Graphischen. Skizze eines Forschungsansatzes. In Androutsopoulos, Jannis \& Florian Busch (eds.), Register des Graphischen. Variation, Interaktion und Reflexion in der digitalen Schriftlichkeit, 1-29. Berlin \& Boston: De Gruyter.

Androutsopoulous, Jannis \& Florian Busch. 2021. Digital punctuation as an interactional resource: The message-final period among German adolescents. Linguistics \& Education 62. 10.1016/j.linged.2020.100871.

Angermeyer, Philipp Sebastian. 2005. Spelling bilingualism. Script choice in Russian American classified ads and signage. Language in Society 34(4). 493-531.

Bakhtin, Michail M. 1986. Speech genres and other late essays (translated by V. W. McGee). Austin, TX: University of Texas Press.

Beißwenger, Michael. 2007. Sprachhandlungskoordination in der Chat-Kommunikation. Berlin \& New York: De Gruyter.

Biber, Douglas. 1994. An analytical framework for register studies. In Douglas Biber \& Edward Finegan (eds.), Sociolinguistic perspectives on register, 31-58. New York: Oxford University.

Biber, Douglas \& Susan Conrad. 2009. Register, genre, and style. Cambridge: Cambridge University.

Blom, Jan-Petter \& John J. Gumperz. 1972. Social meaning in linguistic structure. Codeswitching in Norway. In John J. Gumperz \& Dell H. Hymes (eds.), Directions in sociolinguistics. The ethnography of communication, 407-434. New York: Holt, Rinehart and Winston.

Brown, Roger \& Albert Gilman. 1960. The pronouns of power and solidarity. In Thomas A. Sebeok (ed.), Style in language, 253-276. New York: Wiley.

Bucholtz, Mary \& Kira Hall. 2005. Identity and interaction. A sociocultural linguistic approach. Discourse Studies 7(4/5). 585-614.

Busch, Florian. 2018. Digital writing practices and media ideologies of German adolescents. The Mouth. Critical Studies in Language, Culture and Society 3. 85-103.

Busch, Florian. 2021a. Digitale Schreibregister. Formen, Kontexte und metapragmatische Reflexionen. Berlin \& Boston: De Gruyter.

Busch, Florian. 2021b. The interactional principle in digital punctuation. Discourse, Context \& Media 40. 1-10.

Couper-Kuhlen, Elizabeth \& Margret Selting. 2018. Interactional linguistics. Studying language in social interaction. Cambridge: Cambridge University.

Crystal, David. 2001. Language and the internet. Cambridge: Cambridge University.

Crystal, David. 2008. Txtng. The Gr8 Db8. Oxford: Oxford University.

Cutler, Cecelia. 2020. Metapragmatic comments and orthographic performances of a New York accent on YouTube. World Englishes 39. 36-53.

Danet, Brenda. 2001. Cyberpl@y. Communicating online. Oxford: Berg.

Debenport, Erin \& Anthony K. Webster. 2019. From literacy/literacies to graphic pluralism and inscriptive practices. Annual Review of Anthropology 48. 389-404.

Donaldson, Coleman. 2017. Orthography, standardization, and register: The case of Manding. In Pia Lane, James Costa \& Haley De Korne (eds.), Standardizing minority languages: 
Competing ideologies of authority and authenticity in the global periphery, 175-199. New York: Routledge.

Dürscheid, Christa. 2003. Medienkommunikation im Kontinuum von Mündlichkeit und Schriftlichkeit. Theoretische und empirische Probleme. Zeitschrift für Angewandte Linguistik 38. 37-56.

Eckert, Penelope. 2008. Variation and the indexical field. Journal of Sociolinguistics 12(4). 453-476.

Elspaß, Stephan. 2002. Alter Wein und neue Schläuche? Briefe der Wende zum 20. Jahrhundert und Texte der neuen Medien - ein Vergleich. OBST. Osnabrücker Beiträge zur Sprachtheorie 64. 7-31.

Ferrara, Kathleen, Hans Brunner \& Greg Whittemore. 1991. Interactive written discourse as an emergent register. Written Communication 8(1). 8-34.

Gee, James Paul. 2015. The new literacy studies. In Jennifer Rowsell \& Kate Pahl (eds.), The Routledge handbook of literacy studies, 35-48. New York: Routledge.

Georgakopoulou, Alexandra. 1997. Self-presentation and interactional alignments in e-mail discourse. The style- and code-switches of Greek messages. International Journal of Applied Linguistics 7. 141-164.

Giles, David, Wyke Stommel, Trena Paulus, Jessica Lester \& Darren Reed. 2015. Microanalysis of online data. The methodological development of "digital CA". Discourse, Context \& Media 7. 45-51.

Gumperz, John J. 1982. Discourse strategies. Cambridge: Cambridge University.

Halliday, Michael A. K. 1978. Language as social semiotic. The social interpretation of language and meaning. London: Arnold.

Herring, Susan C. \& Ashley Dainas. 2017. 'Nice picture comment!' Graphicons in Facebook comment threads. In Proceedings of the Fiftieth Hawai'i International Conference on System Sciences (HICSS-50), 2185-2194. Los Alamitos, CA: IEEE.

Hill, Jane H. 1993. Hasta la vista, baby: Anglo Spanish in the American Southwest. Critique of Anthropology 13. 145-176.

Imo, Wolfgang. 2015. Vom Happen zum Häppchen... Die Präferenz für inkrementelle Äußerungsproduktion in internetbasierten Messengerdiensten. Networx 69. 4-35. $10.15488 / 2960$.

Irvine, Judith T. \& Susan Gal. 2000. Language ideology and linguistic differentiation. In Paul V. Kroskrity (ed.), Regimes of language. Ideologies, polities, and identities, 35-84. Santa Fe, NM: School of American Research.

Jaffe, Alexandra. 2000. Introduction. Non-standard orthography and non-standard speech. Journal of Sociolinguistics 4(4). 497-513.

Jaffe, Alexandra. 2016. Indexicality, stance and fields in sociolinguistics. In Nikolas Coupland (ed.), Sociolinguistics. Theoretical debates, 86-112. Cambridge: Cambridge University.

Jaffe, Alexandra, Jannis Androutsopoulos, Mark Sebba \& Sally Johnson (eds.). 2012. Orthography as social action. Scripts, spelling, identity and power. Berlin \& New York: De Gruyter Mouton.

Järlehed, Johan. 2015. Ideological framing of vernacular type choices in the Galician and Basque semiotic landscape. Social Semiotics 25(2). 165-199.

Johnson, Sally. 2005. Spelling trouble. Language ideology and the reform of German orthography. Clevedon: Multilingual Matters.

Kiesling, Scott F. 2004. Dude. American Speech 79(3). 281-305.

Koch, Peter \& Wulf Oesterreicher. 1985. Sprache der Nähe - Sprache der Distanz. Mündlichkeit 
und Schriftlichkeit im Spannungsfeld von Sprachtheorie und Sprachgeschichte. Romanistisches Jahrbuch 36. 15-43.

König, Katharina \& Tim Moritz Hector. 2019. Neue Medien - neue Mündlichkeit? Zur Dialogizität von WhatsApp-Sprachnachrichten. In Konstanze Marx \& Axel Schmidt (eds.), Interaktion und Medien, 59-84. Heidelberg: Winter.

Lillis, Theresa. 2013. The sociolinguistics of writing. Edinburgh: Edinburgh University.

McSweeney, Michelle A. 2018. The pragmatics of text messaging. Making meaning in messages. New York: Routledge.

Neef, Martin \& Beatrice Primus. 2001. Stumme Zeugen der Autonomie - Eine Replik auf Ossner. Linguistische Berichte 187. 353-378.

Neely, Amber \& Gus Palmer Jr. 2009. Which way is the Kiowa way? Orthography choices, ideologies, and language renewal. In Paul V. Kroskrity \& Margaret C. Field (eds.), Native American language ideologies: Beliefs, practices, and struggles in Indian Country, 271-297. Tucson, AZ: University of Arizona Press.

Pappert, Steffen. 2017. Zu kommunikativen Funktionen von Emojis in der WhatsApp-Kommunikation. In Michael Beißwenger (ed.), Empirische Erforschung internetbasierter Kommunikation, 175-212. Berlin \& Boston: De Gruyter.

Romaine, Suzanne. 2005. Orthographic practices in the standardization of pidgins and creoles: Pidgin in Hawai'i as anti-language and anti-standard. Journal of Pidgin and Creole Languages 20(1). 101-140.

Runkehl, Jens, Peter Schlobinski \& Torsten Siever. 1998. Sprache und Kommunikation im Internet. Überblick und Analysen. Opladen: Westdeutscher Verlag.

Schegloff, Emanuel A. 2007. Sequence organization in interaction. Cambridge: Cambridge University.

Schnitzer, Caroline-Victoria. 2012. Linguistische Aspekte der Kommunikation in den neueren elektronischen Medien. SMS - E-Mail - Facebook. München:

Ludwig-Maximilians-Universität München dissertation. https://edoc.ub.uni-muenchen. de/14779/ (accessed 7 October 2019).

Schröder, Ingrid. 2015. Zwischen Dialektologie und Regionalsprachenforschung - eine norddeutsche Perspektivierung. In Michael Elmentaler, Markus Hundt \& Jürgen E. Schmidt (eds.), Deutsche Dialekte. Konzepte, Probleme, Handlungsfelder, 25-57. Stuttgart: Steiner.

Screti, Franceso. 2018. Re-writing Galicia: Spelling and the construction of social space. Journal of Sociolinguistics 22(5). 516-544.

Sebba, Mark. 2007. Spelling and society. The culture and politics of orthography around the world. Cambridge: Cambridge University.

Sebba, Mark. 2009. Sociolinguistic approaches to writing systems research. Writing Systems Research 1(1). 35-49.

Shortis, Tim. 2007. Revoicing Txt. Spelling, vernacular orthography and 'unregimented writing' In Santiago Posteguillo, María José Esteve \& M. Lluïsa Gea-Valor (eds.), The texture of internet. Netlinguistics in progress, 2-23. Newcastle: Cambridge Scholars.

Siebenhaar, Beat. 2020. Informalitätsmarkierung in der WhatsApp-Kommunikation. Ein Vergleich bundesdeutscher und Deutschschweizer Chats. In Androutsopoulos, Jannis \& Florian Busch (eds.), Register des Graphischen. Variation, Interaktion und Reflexion in der digitalen Schriftlichkeit, 67-91. Berlin \& Boston: De Gruyter.

Silverstein, Michael. 1979. Language structure and linguistic ideologies. In Paul R. Clyne, William F. Hanks \& Carol L. Hofbauer (eds.), The elements. A parasession on linguistic units and levels, 213-226. Chicago, IL: Chicago Linguistic Society. 
Silverstein, Michael. 1985. Language and the culture of gender. At the intersection of structure, usage, and ideology. In Elizabeth Mertz \& Richard J. Parmentier (eds.), Semiotic mediation, 219-239. Orlando, FL: Academic Press.

Silverstein, Michael. 2003. Indexical order and the dialectics of sociolinguistic life. Language \& Communication 23(2003). 193-229.

Spiller, Bernd. 2004. Stil / Style. In Ulrich Ammon, Norbert Dittmar, Klaus J. Mattheier \& Peter Trudgill (ed.), Sociolinguistics / Soziolinguistik. An international handbook of the science of language and society / Ein internationales Handbuch zur Wissenschaft von Sprache und Gesellschaft, 206-216. 2nd compl. rev. and extend. edn. Berlin \& New York: De Gruyter.

Spitzmüller, Jürgen. 2007. Graphisches Crossing. Eine soziolinguistische Analyse graphostilistischer Variation. Zeitschrift für Germanistische Linguistik 35(3). 397-418.

Spitzmüller, Jürgen. 2012. Floating ideologies. Metamorphoses of graphic 'Germanness'. In Alexandra Jaffe, Jannis Androutsopoulos, Mark Sebba \& Sally Johnson (eds.), Orthography as social action, 255-288. Berlin \& New York: De Gruyter Mouton.

Spitzmüller, Jürgen. 2013. Graphische Variation als soziale Praxis. Eine soziolinguistische Theorie skripturaler ,Sichtbarkeit‘. Berlin \& New York: De Gruyter.

Stenschke, Oliver. 2005. Rechtschreiben, Recht sprechen, recht haben - der Diskurs über die Rechtschreibreform. Tübingen: Niemeyer.

Storrer, Angelika. 2018. Interaktionsorientiertes Schreiben im Internet. In Arnulf Deppermann \& Silke Reineke (eds.), Sprache im kommunikativen, interaktiven und kulturellen Kontext, 219-244. Berlin \& Boston: De Gruyter.

Tagg, Caroline, Alistair Baron \& Paul Rayson. 2012. 'I didn't spel that wrong did i. Oops'. Analysis and normalisation of SMS spelling variation. Lingvisticæ Investigationes 35(2). 367-388.

Thurlow, Crispin \& Alex Brown. 2003. Generation Txt? The sociolinguistics of young people's text-messaging. Discourse Analysis Online 1(1). https://extra.shu.ac.uk/daol/articles/v1/ n1/a3/thurlow2002003-paper.html (5 October 2019).

Tophinke, Doris. 2002. Schreiben gegen die Regel - Formen und Funktionen orthografischer Abweichungen im Internet Relay Chat (IRC). In Michael Bommes, Christina Noack \& Doris Tophinke (eds.), Sprache als Form. Festschrift für Utz Maas zum 60. Geburtstag, 169-181. Opladen: Westdeutscher Verlag.

Werry, Christopher C. 1996. Linguistic and interactional features of Internet Relay Chat. In Susan C. Herring (ed.), Computer-mediated communication. Linguistic, social and cross-cultural perspectives, 47-64. Amsterdam: John Benjamins. 